\title{
Endogenous Insulin: Study on Pain Threshold through Opioid Mechanism in Swiss Albino Mice
}

\author{
Balasubramaniam Nandhakumar, N. Natham Rajendran* \\ Department of Pharmacology, Department of Pharmaceutics, Swamy Vivekanandha College of Pharmacy and Research Institute, Elayampalayam, \\ Namakkal, Tamil Nadu, INDIA.
}

\begin{abstract}
Background: There is no definitive conclusion on relationship between insulin and pain threshold through opioid mechanism in experimental animal model. The present study investigated the role of endogenous insulin in the modulation of pain using opioid drugs through opioid mechanism and their relationship in experimental animal model. Methods: Eight animal groups were used, each group consisting of six mice (Swiss albino). Group 1-treated saline ip; Group 2- administered pentazocine ip; Group 3- treated naloxone in low dose $(0.005 \mathrm{mg} / \mathrm{kg}$, ip) $15 \mathrm{~min}$ prior to pentazocine treatment; Group 4- administered naloxone in high dose (5 mg/kg, ip) $15 \mathrm{~min}$ prior to pentazocine treatment. Another four groups of animals (Group 5, 6 , 7 and 8) treated saline, pentazocine, low dose and high dose naloxone both administered $15 \mathrm{~min}$ prior to pentazocine treatment respectively. Group 1,2,3 and 4 subjected to acetic acid challenge and Group 5,6, 7 and 8 subjected to formalin test. Blood samples were collected and serum insulin was estimated by ELISA and blood glucose was measured by using Ames glucometer. Results: Pentazocine significantly increased both serum insulin and antinociceptive response to nociceptive stimuli to acetic acid
\end{abstract}

as well as formalin challenge without significantly affecting plasma glucose in both pain models as compared to saline control. Conclusion: The study concluded that possible association between endogenous insulin and pain threshold which is independent of the glycemic status in both the chemically induced nociceptive tests. The relationship between endogenous insulin and pain threshold involves an interaction with opioid system possibly by binding with kappa receptor.

Key words: Endogenous insulin, Plasma glucose, Pentazocine, Pain thresholds, Mice.

\section{Correspondence}

Dr. N N Rajendran,

Professor and HOD, Department of Pharmaceutics, Director, College of Pharmacy, Swamy Vivekanandha College of Pharmacy and Research, Institute, Elayampalayam-637 205, Tamil Nadu, INDIA.

Email id: nnrajendran49@gmail.com

DOI: 10.5530/jyp.2021.13.93

\section{INTRODUCTION}

Exogenous insulin potentiates the anti-nociceptive action of morphine that correlates with insulin induced hypoglycaemia. This finding attracted further works on to investigate whether insulin itself or insulin induced changes in glycemic status influence the pain threshold. Insulin when administered i.c.v produces inherent antinociceptive response without affecting glycemic status to formalin induced nociceptive stimuli in healthy animals and possibly insulin acts as neuromodulator. ${ }^{1}$ Parallel to this finding studies claim that acute hyperglycemia or chronic hyperglycemia induced by STZ does not alter the pain threshold in animal models. Conversely, another study reports that streptozotocin-induced diabetic mice and rats as well as genetically diabetic $\mathrm{db} / \mathrm{db}$ mice are significantly less sensitive to the antinociceptive effect of morphine in tail flick test stating that blood glucose affects pain perception mechanisms. ${ }^{2}$ Further studies support the involvement of insulin in the modulation of pain. In the formalin test in $\mathrm{db} / \mathrm{db}$ mice the authors propose that hyperinsulinemia rather than hyperglycemia potentiates the analgesic effect of morphine and that hyperinsulinemia compensates for the attenuated pain perception mechanism due to hyperglycemia. Insulinopenia elicits hyperalgesia and insulin replacement normalizes pain threshold irrespective of the glycemic status in diabetic rat and in support of this another study claims that insulin deficit with impaired insulin signalling rather than hyperglycemia plays a role in the modulation of pain threshold in diabetic animals. ${ }^{3}$ Besides the animal studies, few clinical studies support the involvement of insulin in the modulation of pain threshold.
Normal subjects with higher insulin levels show elevated pain threshold for thermal nociceptive stimuli and serum insulin level is higher in praderwilli syndrome. ${ }^{4}$ Most studies carried out so far support the relation between insulin and antinociception through opioid pathway. However, whether such a relation is independent of the glycemic status has not been clearly established. Naloxone, the opioid antagonist has been reported to influence serum insulin in antinociceptive effect of flavone, the basic compound of flavonoids that has been established as an opioid compound. While low dose naloxone potentiates the antinociceptive effect of flavone associated with increase in serum insulin, high dose antagonised the anti-nocciceptive effect of flavone with decrease in serum insulin, in both treatments, the glycemic status remains unchanged. ${ }^{5}$ These findings raise the question whether endogenous insulin has a role to play in antinociceptive effect of opioids and whether the effect is independent of the glycemic status. Based on the literature survey, it was observed that there is no investigation on relationship between endogenous insulin and antinociception with currently used opioid analgesics and also its influence on glycemic status. Further, it was found that pentazocine is the commonly used opioid analgesic in clinical practice. With this information, the present study designed to investigate the role of endogenous insulin in the modulation of pain using opioid drugs through opioid mechanism and their relationship in experimental animal model.

This is an open access article distributed under the terms of the Creative Commons Attribution-NonCommercial-ShareAlike 4.0 License, which allows others to remix, tweak, and build upon the work non-commercially, as long as the author is credited and the new creations are licensed under the identical terms. 


\section{MATERIALS AND METHODS}

\section{Animals}

Healthy Swiss albino mice (Male; 20-25 g) were used in the study.Mice were procured from Institutional Animal House, SwamyVivekanandha College of Pharmacy, Elayampalayam (Tamilnadu, India). Experimental protocol (SVCP/IAEC/Ph.D/01/2011) was approved by Institutional Animal Ethics Committee formed under regulation of the Committee for the Purpose of Control and Supervision of Experiments on Animals (CPCSEA), Ministry of Environment and Forests, Government of India. All the mice were acclimatized to the laboratory condition before experiments. All the mice were housed with 12:12 h light: dark cycle, $25 \pm 2^{\circ} \mathrm{C}$ of temperature, and humidity (approximately 50\%) in the normal laboratory conditions. For the whole study, the mice have been fed normal food and water with ad libitum. Food was withdrawn $12 \mathrm{hr}$ prior to experiments and water was provided ad libitum.

\section{Drugs and Chemicals}

Pentazocine lactate was procured from Ranbaxy Pharma, India). Naloxone hydrochloride was procured from Endo Labs, USA. Glacial acetic acid and formalin was procured from LobaChemie, India. Insulin ELISA kit was procured from Cal Biotech Inc., Spring Valley, USA.

\section{Grouping of Animals}

The grouping of the animals in behavioural pain models was as follow:

\section{Acetic acid-induced abdominal constrictions method}

- Group 1- Mice treated saline -(intraperitoneally (ip))

- Group 2- Mice administered pentazocineip

- Group 3- Treated naloxone in low dose (0.005 mg/kg, ip) $15 \mathrm{~min}$ prior to pentazocine treatment

- Group 4- Mice administered naloxone in high dose (5 mg/kg, ip) 15 min prior to pentazocine treatment

\section{Formalin-induced method}

- Group 5- Mice treated saline - (intraperitoneally (ip))

- Group 6- Mice administered pentazocine (ip)

- Group 7- Mice treated naloxone in low dose $(0.005 \mathrm{mg} / \mathrm{kg}$, ip) 15 min prior to pentazocine treatment

- Group 8- Mice administered naloxone in high dose (5 mg/kg, ip) 15 min prior to pentazocine treatment

\section{Behavioural pain models}

\section{Acetic acid induced abdominal constrictions method}

Animals received $10 \mathrm{ml} / \mathrm{kg}$ of $0.6 \%$ freshly prepared acetic acid intraperitoneally. The number of abdominal constrictions $15 \mathrm{~min}$ following this injection was recorded and considered as nociceptive response. A significant reduction in number of abdominal constrictions $(P<0.05$ level) was considered as an antinociceptive response. Every animal was exposed to this test only once to avoid the fluctuation in the responses due to the neural damage by acetic acid. ${ }^{6}$

\section{Formalin induced method}

50 microlitre of $1 \%$ formalin in saline was administered s.c into the plantar surface of the left hind paw. The time in seconds spent in licking and biting the injected paw was recorded. The early phase of nociceptive response normally peaks from 0 to $10 \mathrm{~min}$ and the late phase from 10 to $30 \mathrm{~min}$ after formalin injection. In the present study, we studied late phase only. The time in seconds spent in licking and biting the formalin injected paw from 10 to $30 \mathrm{~min}$ was recorded. A significant reduction in response time from 10 to $30 \mathrm{~min}$ period $(P<0.05$ level) was considered as an antinociceptive response. All six animals in a group were exposed to this test only once to avoid the fluctuation in the responses. ${ }^{7}$

\section{Role of opioid system}

The role of kappa receptor opioid system on the involvement of endogenous insulin in pain threshold was investigated using naloxone in mice. Naloxone $(5 \mathrm{mg} / \mathrm{kg}$, ip) was employed to study the possible role endogenous insulin via opioid system. Naloxone in low dose was used in combination with pentazocine to produce potentiated analgesic response. Naloxone in low as well as high doses was administered $15 \mathrm{~min}$ prior to pentazocine treatment.

\section{Biochemical estimations}

\section{Estimation of plasma glucose}

Blood was collected by cutting the tip of the tail of mice and plasma glucose was estimated by AMES Glucometer (Bayer's Diagnostics, Mumbai, India). The measurement of plasma glucose was recorded prior to the exposure of any drug/nociception to the animal, after the drug treatment; just before the nociceptive challenge and at the end of nociceptive challenge. The results were expressed as percentage change in the blood glucose considering the initial blood glucose value of that animal as $100 \%$.

\section{Estimation of serum insulin}

One $\mathrm{ml}$ of blood was collected by tail vein method before and after respective treatment. It was allowed to stand for $10 \mathrm{~min}$ and serum was collected from the blood by centrifuging the tubes at $3000 \mathrm{rpm}$ in centrifuge (REMI, Mumbai). The serum was separated in serum tubes and it was stored at $4^{\circ} \mathrm{C} \pm 1^{\circ} \mathrm{C}$. The serum insulin level was estimated usinginsulin enzyme linked immunosorbent assay kit (Cal Biotech Inc., Spring Valley, USA).

\section{Protein-protein docking method}

The possible interaction between human insulin (PDB code: 4EY1) and human kappa opioid receptor (PDB code: $4 \mathrm{DJH}$ ) by protein - protein docking method is studied using clusPro2.0 program.

\section{Statistical Analysis}

The obtained data was analysed by using one way ANOVA followed by Dunnett's ' $t$ ' test. $P$-values less than 0.05 were considered to indicate statistical significance. All values were expressed as the mean \pm S.E.M.

\section{RESULTS}

\section{Abdominal constriction assay}

The data of abdominal constriction assay are shown in Table 1 . The mean number of abdominal constrictions, serum insulin level and blood glucose level after i.p. injection of acetic acid was $32.0 \pm 0.73,13.2 \pm 0.15$ and $106.49 \pm 3.47$ respectively in vehicle treated control animals $(n=6)$. A significant reduction in abdominal constrictions $(15.33 \pm 0.33 ; P<0.01)$ with increase in serum insulin $(p<0.01)$ was observed in pentazocine treated mice as compared to vehicle control. No significant change in blood glucose was found between pentazocine and vehicle treatments. Pre-treatment with low-dose naloxone $(0.005 \mathrm{mg} / \mathrm{kg}$, i.p.) showed significant reduction in the number of abdominal constrictions $(P<0.01)$ with elevated serum insulin $(P<0.01)$ as compared to pentazocine; whereas high dose naloxone ( $5 \mathrm{mg} / \mathrm{kg}$, i.p) reversed pentazocine induced reduction in abdominal constrictions $(p<0.01)$ as well as elevated increase in serum insulin as compared to pentazocine. Both low and high dose naloxone did not produce significant change in blood glucose. 
Table 1: The relation between serum insulin, blood glucose and pain threshold in acetic acid induced abdominal constrictions in mice.

\begin{tabular}{cccc}
\hline $\begin{array}{c}\text { Treatment } \\
(\mu \mathrm{lU} / \mathrm{mL})\end{array}$ & Serum insulin & $\begin{array}{c}\text { Number of } \\
\text { abdominal } \\
\text { constrictions }\end{array}$ & $\begin{array}{c}\text { Blood glucose } \\
(\%)\end{array}$ \\
\hline Control & $13.20 \pm 0.15$ & $32.0 \pm 0.73$ & $106.49 \pm 3.47$ \\
Pentazocine 4 & $15.83 \pm 0.30^{\mathrm{a}}$ & $15.33 \pm 0.33^{\mathrm{a}}$ & $103.99 \pm 3.50$ \\
Naloxone 5 & $11.33 \pm 0.34^{\mathrm{a}}$ & $31.66 \pm 0.84$ & $104.38 \pm 3.03$ \\
Naloxone 0.005 & $17.55 \pm 0.20^{\mathrm{a}, \mathrm{b}}$ & $11.83 \pm 0.48^{\mathrm{a}, \mathrm{b}}$ & $102.88 \pm 3.74$ \\
\hline
\end{tabular}

Each value represents mean \pm SEM of six observations.

${ }^{\text {a }} P<0.01$ compared with control.

${ }^{\mathrm{b}} P<0.01$ compared with pentazocine treatment.

Table 2: The relation between serum insulin, blood glucose and pain threshold in formalin induced nociception in mice (chronic phase).

\begin{tabular}{cccc}
\hline $\begin{array}{c}\text { Treatment } \\
(\mu \mathrm{lU} / \mathrm{mL})\end{array}$ & Serum insulin & $\begin{array}{c}\text { Paw licking } \\
\text { response time in } \\
\text { seconds }\end{array}$ & $\begin{array}{c}\text { Blood glucose } \\
(\%)\end{array}$ \\
\hline Control & $14.11 \pm 0.20$ & $87.5 \pm 0.43$ & $110.61 \pm 5.01$ \\
Pentazocine 30 & $19.15 \pm 0.27^{\mathrm{a}}$ & $52.83 \pm 0.65^{\mathrm{a}}$ & $108.38 \pm 5.18$ \\
Naloxone 5 & $13.63 \pm 0.35$ & $86.83 \pm 1.01$ & $109.37 \pm 4.69$ \\
Naloxone 0.005 & $20.46 \pm 0.26^{\mathrm{a}, \mathrm{b}}$ & $44.50 \pm 0.56^{\mathrm{a}, \mathrm{b}}$ & $105.45 \pm 4.41$ \\
\hline
\end{tabular}

Each value represents mean \pm SEM of six observations.

${ }^{\mathrm{a}} P<0.01$ compared with control.

${ }^{\mathrm{b}} P<0.01$ compared with pentazocine treatment.

\section{Formalin induced nociceptive test}

The results of formalin induced nociceptive test are given in Table 2. In vehicle treated control mice the mean paw licking response time, serum insulin and blood glucose after subcutaneous injection of formalin into the right hind paw was $87.5 \pm 0.43 \mathrm{~s}, 14.11 \pm 0.20,110.61 \pm 5.01$ respectively in the chronic phase. Pentazocine treatment resulted in a marked reduction of response time to $52.83 \pm 0.65 \mathrm{~s}(p<0.01)$ with significant increase in serum insulin level $(P<0.01)$; however, no significant change in blood glucose was observed as compared to vehicle control. Pre-treatment with low-dose naloxone $(0.005 \mathrm{mg} / \mathrm{kg}$, i.p.) produced significant reduction in response time $(P<0.01)$ with significant increase in serum insulin $(P<0.01)$ as compared to pentazocine. High dose naloxone $(5 \mathrm{mg} / \mathrm{kg}$, i.p) significantly reversed the reduction in response time $(p<0.01)$ and the increase in serum insulin elicited by pentazocine $(p<0.01)$. No significant change in blood glucose was observed with low as well as high dose naloxone.

\section{Analysis of opioid mediated mechanism}

The effect of naloxone, an opioid antagonist on the antinociceptive response and the changes in serum insulin and blood glucose induced by pentazocine was studied. As shown in Table 1 and 2, pretreatment of mice with naloxone $(5 \mathrm{mg} / \mathrm{kg}$, i.p.) significantly antagonized the antinociceptive effects and the increase in serum insulin effected by pentazocine in both acetic acid assay and formalin induced nociceptive test; however, blood glucose was not significantly altered.

\section{Protein-protein docking method}

The interactions between protein chains and the experimental data are shown in Figure 1 and Figure 2 and Table 3 and 4 . The interaction if any, between insulin and opioid receptors was studied by protein-protein docking method using clusPro 2.0. Program and the result showed insulin binding with kappa receptor through hydrogen bonding.

\section{DISCUSSION}

Pain is a complex phenomenon and several chemical mediators, neurotransmitters and neuropeptides are involved in pain perception. ${ }^{8}$ In the recent past, the involvement of insulin in pain threshold has assumed significance. Insulin potentiates the antinociceptive response of sodium salicylate and morphine and I.C.V. injection of insulin dose

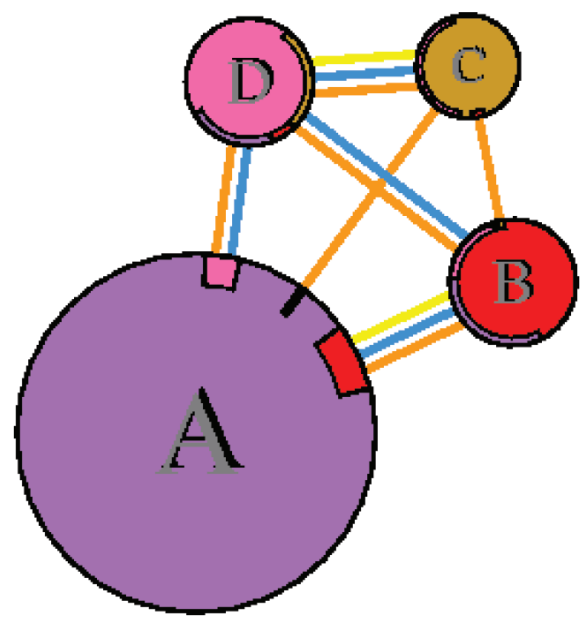

Key: $\begin{array}{llll}\text { Salt } & \text { Disulphide } & \text { Hydrogen } & \text { Non-bonded } \\ \text { bridges } & \text { bonds } & \text { bonds } & \text { contacts }\end{array}$

Figure 1: Schematic diagram of interactions between protein chains. Interacting chains are joined by coloured lines, each representing a different type of interaction, as per the key above. The area of each circle is proportional to the surface area of the corresponding protein chain. The extent of the interface region on each chain is represented by a coloured wedge whose colour corresponds to the colour of the other chain and whose size signifies the interface surface area. Statistics for all the interfaces are given below.

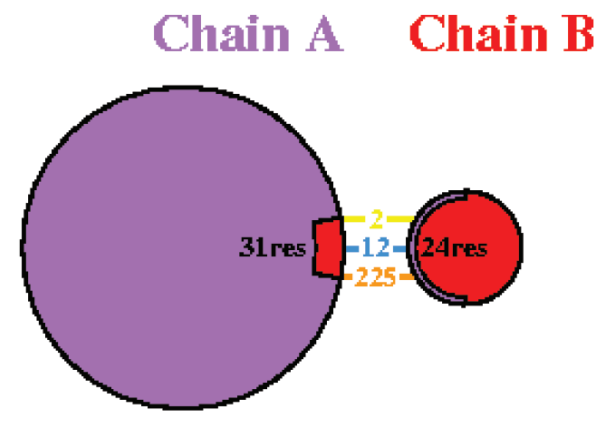

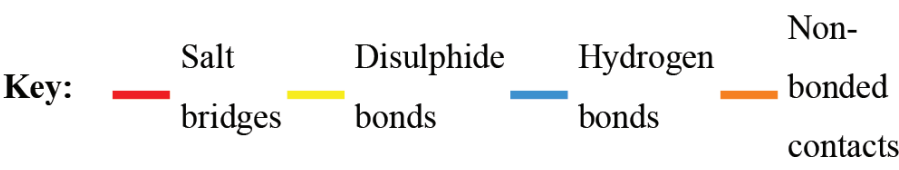

Figure 2: Schematic diagram of interactions between protein chains. Interacting chains are joined by coloured lines, each representing a different type of interaction, as per the key above. The area of each circle is proportional to the surface area of the corresponding protein chain. The extent of the interface region on each chain is represented by the black wedge whose size signifies the interface surface area. 
Table 3: Interface statistics.

\begin{tabular}{|c|c|c|c|c|c|c|}
\hline $\begin{array}{l}\frac{n}{\pi} \\
\frac{\tilde{S}}{U}\end{array}$ & 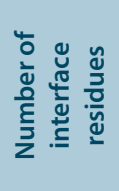 & 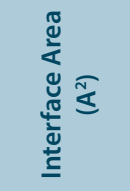 & 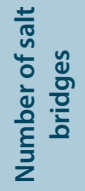 & 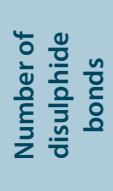 & 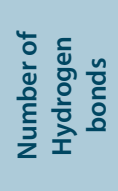 & 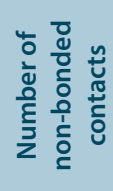 \\
\hline A-B & $31: 24$ & $1538: 1604$ & - & 2 & 12 & 225 \\
\hline A-C & $2: 1$ & $131: 150$ & - & - & - & 3 \\
\hline A-D & $17: 13$ & 799:916 & - & - & 4 & 69 \\
\hline B-C & $2: 1$ & $60: 81$ & - & - & - & 5 \\
\hline B-D & $13: 14$ & $585: 564$ & - & - & 9 & 107 \\
\hline C-D & $16: 18$ & $900: 879$ & - & 2 & 8 & 144 \\
\hline
\end{tabular}

Table 4: Interface statistics.

\begin{tabular}{|c|c|c|c|c|c|c|}
\hline $\begin{array}{l}\frac{\tilde{c}}{\pi} \\
\frac{\tilde{U}}{U}\end{array}$ & 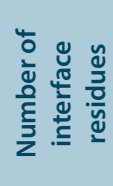 & 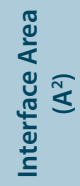 & 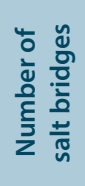 & 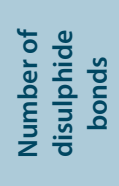 & 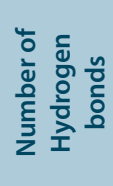 & 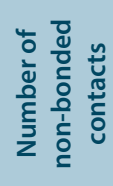 \\
\hline A & 31 & 1538 & - & 2 & 12 & 225 \\
\hline B & 24 & 1604 & - & - & - & - \\
\hline
\end{tabular}

dependently lower the second phase of formalin induced pain with no change in blood glucose suggesting participation of opioid mechanism in insulin on pain threshold. ${ }^{9,10}$

In addition, an insulin deficit with impaired insulin signalling and neurotrophic support, rather than hyperglycemia, plays an essential role in the pathophysiology of painful diabetic neuropathy. Besides, consequences of insulinemia or insulinemia itself may play an important role in early impairment of mechanical nociception in diabetic animal model and duration of diabetes alters pain threshold in diabetic mice after STZ treatment in tail flick method. ${ }^{11,12}$

Our study demonstrated that pentazocine induced antinociception influenced the endogenous insulin without altering the glycemic status and suggested that there could be a relation between endogenous insulin and opioid mediated antinociception. The results of the study was limited to kappa receptor agonist as selected in this study and as such cannot be extrapolated to other opioid receptor agonists.

In order to estimate the level of endogenous insulin during painful condition using behavioural nociceptive tests, it is essential to employ different tests which differ in stimulus quality, intensity and duration. Keeping this in view two different pain models such as acetic acid and formalin were chosen in the study. Acetic acid induced assay is regarded as a very sensitive method for visceral nociception employing minimal noxious stimulus. Formalin induced nociception represents neurogenic (early phase) and inflammatory (late phase) pain behaviour. ${ }^{13}$

In our study, pentazocine an opioid analgesic is the preferred drug in clinical practice for the management of pain and furthermore study on its interaction with endogenous insulin in the modulation of pain is lacking and therefore was selected. Pentazocine did not significantly influence the blood glucose, however attenuated nociception associated with significant increase in endogenous insulin and the effect was found to be independent of the nociceptive test employed. However the endogenous insulin level is pain intensity dependent could not be established in the study. The effect of naloxone in low as well as high dose on the involvement of endogenous insulin in pain threshold in the two chemically induced pain models was investigated. High dose naloxone significantly attenuated the antinociceptive effect of pentazocine and lowered the endogenous insulin without significantly affecting the blood glucose in both pain models. Conversely low dose naloxone potentiated pentazocine induced antinociception associated with increase in endogenous insulin with no change in blood glucose in both nociceptive tests employed. Our findings suggest that pentazocine or naloxone treatments influence the endogenous insulin in eliciting opioid mediated anti-nociception.

\section{CONCLUSION}

This study concluded that insulin has its role in the modulation of pain involving opioid pathway. The results of the protein - protein docking method points to suggest the possible interaction between insulin and opioid receptors, more specifically, the kappa receptor through hydrogen bonding; however, investigation of the active site of either receptor or the residues of insulin involved in binding is in progress. To substantiate this, the results of the study showed significant increase in insulin level in response to pentazocine (kappa receptor agonist) treatment as compared to control and therefore it is suggested that endogenous insulin may interact with opioid system possibly through kappa receptors in the modulation of pain. The present study revealed that there is no direct relation between blood glucose and antinociception; however, involvement of endogenous insulin in pain threshold through opioid pathway by binding possibly with kappa receptor which is independent of the glycemic status in both the chemically induced pain models employed.

\section{ACKNOWLEDGEMENT}

Authors are thankful to Management of Swamy Vivekanandha College of Pharmacy and Research Institute (SVCPRI), Elayampalayam, for providing necessary facilities and for their support to carry out this research project. The authors acknowledge with thanks the technical help rendered by Mr. Balaji Bhaskar, Dept. of Pharmacology, SVCPRI, Elayampalayam.

\section{CONFLICT OF INTEREST}

The authors declare no conflict of interest.

\section{REFERENCES}

1. Davis WM, Miya TS, Edwards LD. The influence of glucose and insulin pretreatment upon morphine analgesia in the rat. J Am Pharm Assoc Am Pharm Assoc. 1956;45(1):60-2. doi: 10.1002/jps.3030450118, PMID 13278266.

2. Takeshita N, Yamaguchi I. Insulin Attenuates formalin induced nociceptive response in mice through a mechanism that is deranged by diabetis mellitus. J PharmacolExpTher. 1996;7:281-5.

3. Schulingkamp RJ, Pagano TC, Hung D, Raffa RB. Insulin receptors and insulin action in the brain: review and clinical implications. Neurosci Biobehav Rev. 2000;24(8):855-72. doi: 10.1016/s0149-7634(00)00040-3, PMID 11118610

4. Priano L, Miscio G, Grugni G, Milano E, Baudo S, Sellitti L, Picconi R, Mauro A. On the origin of sensory impairment and altered pain perception in PraderWilli syndrome: a neurophysiological study. Eur J Pain. 2009;13(8):829-35. doi: 10.1016/j.ejpain.2008.09.011, PMID 18986815.

5. Rajendran NN, Thirugnanasambandam P, Parvathavarthini S, Viswanathan S, Ramaswamy S. Modulation by insulin rather than blood glucose of the pain threshold in acute Physiological and flavone induced antinociception in mice. Indian J Exp Biol. 2001;39(10):1009-16. PMID 11883508.

6. Koster R, Anderson M, DeeBeer AJ. Acetic acid for analgesic screening. Proc. 1959; 18:412-6.

7. Tiølsen A, Berge OG, Hunskaar S, Rosland JH, Hole K. The formalin test: an evaluation of the method. Pain. 1992;51(1):5-17. doi: 10.1016/0304-3959(92)90003-T, PMID 1454405

8. Wisniewski K, Zarebski M. Effect of insulin on the transport and the analgesic action of sodium salicylates. Metabolism. 1968;17(3):212-7. doi: 10.1016/00260495(68)90124-8, PMID 5640773.

9. Singh IS, Chatterjee TK, Ghosh JJ. Modification of morphine antinociceptive response by blood glucose status: possible involvement of cellular energetics. Eur J Pharmacol. 1983;90(4):437-9. doi: 10.1016/0014-2999(83)90568-x, PMID 6350025 . 
10. Calcutt NA, Jorge MC, Yaksh TL, Chaplan SR. Tactile allodynia and formalin hyperalgesia in streptozotocin-diabetic rats: effects of insulin, aldose reductase inhibition and lidocaine. Pain. 1996;68(2-3):293-9. doi: 10.1016/s03043959(96)03201-0, PMID 9121817.

11. Romanovsky D, Hastings SL, Stimers JR, Dobretsov M. Relevance of hyperglycemia to early mechanical hyperalgesia in streptozotocin-induced diabetes. J Peripher Nerv Syst. 2004;9(2):62-9. doi: 10.1111/j.1085-9489.2004.009204.x, PMID 15104693
12. Kamei J, Ohsawa M, Sodeyama M, Kimura M, Tanaka S. Intraventricular insulin reduces the antinociceptive effect of [D-Ala2, NMePhe4, Gly-ol5] enkephalin in mice. Eur J Pharmacol. 1998;345(2):171-4. doi: 10.1016/s0014-2999(98)00004-1, PMID 9600633.

13. Bhaskar M, Jagtap AG. Exploring the possible mechanisms of action behind the antinociceptive activity of Bacopa monniera. Int J Ayurveda Res. 2011;2(1):2-7. doi: 10.4103/0974-7788.83173, PMID 21897636.

Article History: Received: 14-09-2021; Revised: 04-10-2021; Accepted: 11-11-2021.

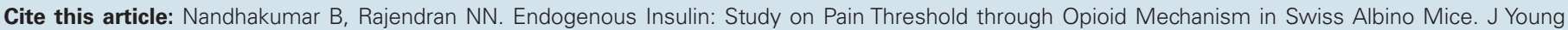
Pharm. 2021;13(4):381-5. 